\title{
EMERGENCE OF FLUOROQUINOLONE-RESISTANT Neisseria gonorrhoeae IN SÃO PAULO, BRAZIL
}

\author{
Walter Belda Junior ${ }^{1}$; Paulo Eduardo Neves Ferreira Velho ${ }^{2 *}$; Marcelo Arnone ${ }^{3}$; Luis Jorge Fagundes ${ }^{4}$ \\ ${ }^{1,3}$ Departamento de Dermatologia, Faculdade de Medicina, Universidade de São Paulo, São Paulo, SP, Brasil; ${ }^{2}$ Departamento de \\ Clínica Médica, Faculdade de Ciências Médicas, Universidade Estadual de Campinas, Campinas, SP, Brasil; ${ }^{4}$ Faculdade de \\ Saúde Pública, Universidade de São Paulo, São Paulo, SP, Brasil
}

Submitted: November 09, 2006; Returned to authors for corrections: January 11, 2007; Approved: March 15, 2007.

\begin{abstract}
Continued monitoring of antimicrobial resistance patterns is essential in order for Sexually Transmitted Diseases (STD) treatment to be effective. Gonococci isolates from 65 patients in São Paulo were submitted to susceptibility testing, and a decreased susceptibility or resistance to ciprofloxacin was observed in $8.7 \%$ of these patients, indicating that Neisseria gonorrhoeae fluoroquinolone resistance is emerging in Brazil.
\end{abstract}

Key words: Anti-Bacterial Agents, Ciprofloxacin, Drug Resistance, Neisseria gonorrhoeae

Despite a sharp decline in the incidence of gonococci infections in developed countries during the last decade, gonorrhea remains one of the most common sexually transmitted infections in developing countries and is a global health problem (9). This emerging resistance of Neisseria gonorrhoeae to antimicrobial agents, resulting from both wide dissemination of resistant clones and strains with novel resistance mechanisms, is a major obstacle in gonorrhea control (8).

Strategies for gonorrhea control have relied on the use of highly effective and often single-dose therapies administered at the time of diagnosis. In response to the emergence of penicillinase-producing $N$. gonorrhoeae, $N$. gonorrhoeae with plasmid-mediated tetracycline resistance and $N$. gonorrhoeae with chromosomally mediated resistance to penicillin and/or tetracycline, the Centers for Disease Control and Prevention (CDC) has advocated the use of expanded-generation cephalosporins or fluoroquinolones as first-line therapy for uncomplicated gonorrhea $(4,19)$. However, strains exhibiting decreased susceptibility to ciprofloxacin have been reported from many countries; strains exhibiting clinically significant resistance to $\mathrm{CDC}$ recommended doses of ciprofloxacin (500 $\mathrm{mg}$ orally, single-dose) or ofloxacin (400 mg, single-dose) have been reported from Asia, Australia, United Kingdom, United States and Canada (5,11,14-17).
In Brazil, ciprofloxacin is one of the recommended therapies for gonorrhea.

Sixty-five strains of $N$. gonorrhoeae isolates from 70 male outpatients with uncomplicated urethritis were collected from 2004 to 2005 and successfully tested for ciprofloxacin susceptibility. They were attended at the Sexually Transmitted Disease Service of the University of São Paulo Teaching Hospital.

Clinical samples were collected according to local procedures. Initial growth on Thayer-Martin and presumptive identifications based on Gram stain, colony morphology, carbohydrate use, and oxidase test were carried out (10). MIC was determined by the agar dilution method, as recommended by the National Committee for Clinical Laboratory Standards (16). Isolates with $\mathrm{MIC}$ of $\geq 1.0 \mu \mathrm{g} / \mathrm{ml}$ for ciprofloxacin were considered resistant, whereas intermediate susceptibility was defined as MIC of 0.12 to $0.5 \mu \mathrm{g} / \mathrm{ml}$ (12). The results of the isolates were: $3.07 \%$ resistant to ciprofloxacin (MIC $\geq 1.0 \mu \mathrm{g} / \mathrm{ml}$ ); $4.61 \%$ presented reduced susceptibility and $92.3 \%$ susceptible (Fig. 1).

Fluoroquinolones, such as ciprofloxacin or ofloxacin, are highly effective as an oral single-dose treatment for uncomplicated infections caused by gonococci strains, including those with previously documented types of resistance $(3,6)$.

The increase in fluoroquinolone resistance has also been substantial in some countries: in Hong Kong, it increased from

*Corresponding Author. Mailing address: Cidade Universitária “Zeferino Vaz”, s/n, Barão Geraldo, Campinas, São Paulo - 13083-970. Tel.: (19) 3289-

4107. E-mail: pvelho@unicamp.br 


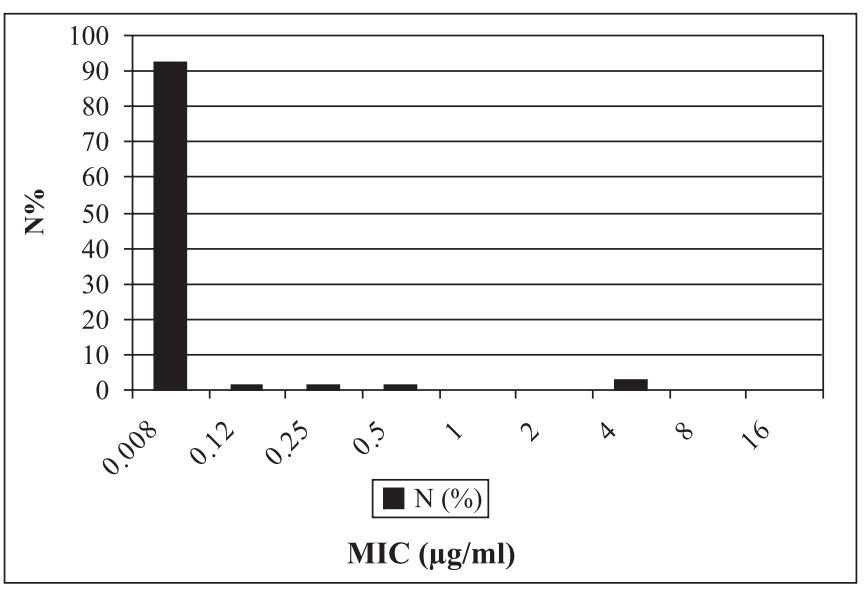

Figure 1. Distribution of the 65 strains of $N$. gonorrhoeae, according to MIC of ciprofloxacin.

$\mathrm{N} \%$ : percentage of strains of $N$. gonorrhoeae

$7.7 \%$ in 1995 to $24 \%$ in 1996; in Singapore, it increased from $0.3 \%$ in 1993 to $3.5 \%$ in 1996; and in Australia it increased from $0.1 \%$ in 1992 to $2.6 \%$ in 1996 (9). Recently the gonococci resistance to fluoroquinolone antimicrobials, ciprofloxacin in particular, is emerging all over the world, such as in Austria, Korea, Japan, United States, and Canada $(2,13,14,18,20)$, and seriously compromises the treatment efficacy. In Brazil it had not been demonstrated before $(1,7)$.

Periodic monitoring of the antimicrobial susceptibility profile of $N$. gonorrhoeae strains provides essential clues regarding the emergence of drug resistance and treatment options.

This communication indicates that $N$. gonorrhoeae fluoroquinolone resistance is emerging in Brazil with these firstfive strains of gonococci exhibiting decreased susceptibility or resistance to ciprofloxacin, which is one of the protocol choices for gonorrhea treatment.

\section{RESUMO}

\section{Emergência de Neisseria gonorrhoeae resistente à fluoroquinolona em São Paulo, Brasil}

O monitoramento contínuo de resistência antimicrobiana é essencial para a efetividade do tratamento das Doenças Sexualmente Transmissíveis (DST). Gonococos isolados de 65 pacientes de São Paulo foram submetidos a teste de susceptibilidade verificando-se que $8,7 \%$ apresentavam susceptibilidade diminuída ou resistência ao ciprofloxacino, o que indica que a resistência da Neisseria gonorrhoeae às fluoroquinolonas é emergente no Brasil.

Palavras-chave: Agentes Antibacterianos, Ciprofloxacino, Resistência a Drogas, Neisseria gonorrhoeae

\section{REFERENCES}

1. Barreto, N.A.; Sant'anna, R.R.P.; Silva, L.B.G.; Uehara A.A.; Guimarães, R.C.; Duarte I.M.; Asensi M.D. (2004). Phenotypic and molecular characterization of Neisseria gonorrhoeae isolated in Rio de Janeiro, Brazil, 2002-2003. DST - J. bras. Doenças Sex. Transm., 16(3), 32-42.

2. Bauer, H.M.; Mark, K.E.; Samuel, M.; Wang, S.A.; Weismuller, P.; Moore, D.; Gunn, R.A.; Peter, C.; Vannier, A.; DeAugustine, N.; Klausner, J.D.; Knapp, J.S.; Bolan, G. (2005). Prevalence of and associated risk factors for fluoroquinolone-resistant Neisseria gonorrhoeae in California; 2000-2003. Clin. Infect. Dis., 41, 795801.

3. Bryan, J.P.; Hira, S.K.; Brady, W.; Liro, N.; Mwale, C.; Mpoko, G.; Krieg, R.; Siwiwaliondo, E.; Reichart, C.; Waters, C.; Perine, P. (1990). Oral ciprofloxacin versus ceftriaxone for the treatment of urethritis from resistant Neisseria gonorrhoeae in Zambia. Antimicrob. Agents Chemother., 34, 819-822.

4. Centers for Disease Control and Prevention. (1998). Sexually transmitted diseases treatment guidelines. Morb. Mortal. Wkly. Rep., $47,59-63$.

5. Centers for Disease Control and Prevention. (2000). Fluoroquinolone- resistance in Neisseria gonorrhoeae, Hawaii, 1999, and decreased susceptibility to azithromycin in $N$. gonorrhoeae, Missouri, 1999. Morb. Mortal. Wkly. Rep., 22, 833-837.

6. Covino, J.M.; Cummings, M.; Smith, B.; Benis, S.; Draft, K.; McCormak, W.M. (1990). Comparison of ofloxacin and ceftriaxone in the treatment of uncomplicated gonorrhea caused by penicillin producing and non-penicillin producing strains. Antimicrob. Agents Chemother., 34, 148-149.

7. Ferreira W.A.; Ferreira C.M.; Schettini A.P.M.; Sardinha J.C.G.; Benzaken A.S.; Garcia M.A.; Garcia E.G.; Oliveira L.A. (2004). Neisseria gonorrhoeae betalactamase producers resistant to azithromycin in Manaus, Amazonas, Brazil. DST - J. bras. Doenças Sex. Transm., 16(2), 28-32.

8. Ison, C.A.; Pepin, J.; Roope, N.S.; Dimba, E.; Seaka, O.; Easmon, C.S.F. (1992). The dominance of a multiresistant strain of Neisseria gonorrhoeae among prostitutes and STD patients in the Gambia. Genitourin. Med., 68, 356-360.

9. Ison, C.A.; Dillon, J.A.; Tapsall, J.W. (1998). The epidemiology of global antibiotic resistance among Neisseria gonorrhoeae and Haemophilus ducreyi. Lancet, 351, 8-11.

10. Knapp, J.S.; Rice, R.J. (1995). Neisseria and Brahamella. In: Baron E., Pfaller M.A., Tenoker F.C., Yolken R.H. (eds). Manual of clinical microbiology. Asm. Press. Washington, DC, USA. p.324-340.

11. Knapp, J.S.; Fox, K.K.; Trees, D.L.; Whittington, W.C. (1997). Fluoroquinolone resistance in Neisseria gonorrhoeae. Emerg. Infect. Dis., 3, 33-39.

12. National Committee for Clinical Laboratory Standards (2002). Performance standards for antimicrobial susceptibility testing. Twelfth International Supplement., 53-55.

13. Ng, L.K.; Sawatzky, P.; Martin, I.E.; Booth, S. (2002). Characterization of ciprofloxacin resistance in Neisseria gonorrhoeae isolates in Canada. Sex. Transm. Dis., 29, 780-788.

14. Tanaka, M.; Nakayama, H.; Haraoka, M.; Saika, T.; Kobayashi, I.; Naito, S. (2000). Antimicrobial resistance of Neisseria gonorrhoeae and high prevalence of ciprofloxacin-resistant isolates in Japan, 1993 to 1998. J. Clin. Microbiol., 38, 521-525.

15. Tanaka, M.; Nakayama, H.; Notomi, T.; Iries, S.; Tsunoda, Y.; Okadome, A.; Saika, T.; Kobayashi, I. (2004). Antimicrobial resistance of Neisseria gonorrhoeae in Japan, 1993-2002: continuous increasing of ciprofloxacin-resistant isolates. Int. J. Antimicrob. Agents, 24, 515-522.

16. Tapsall, J. (1999). Annual report of the Australian gonococcal surveillance program, 1999. Commun. Dis. Intell., 24, 113-117. 
17. Trees, D.L.; Sirivongrangson, P.; Schultz, A.J.; Buatiang, A.; Neal, S.W.; Knapp, J.S.; Kilmarx, P.H. (2002). Multiclonal increase in ciprofloxacin-resistant Neisseria gonorrhoeae, Thailand, 19981999. Sex. Transm. Dis., 29, 668-673.

18. Uthman, A.; Heller-Vitouch, C.; Stary, A.; Bilinc, A.; KuchinkaKoch, A.; Soltz, J.; Tschachler, E. (2004). High frequency of quinolone-resistant Neisseria gonorrhoeae in Austria with a common pattern of triple mutations in GyrA and Par C genes. Sex. Transm. Dis., 31, 616-618.

19. Workowiski, K.A. (2000). The 1998 CDC sexually transmitted diseases treatment guidelines. Curr. Infect. Dis. Rep., 2, 44-50.

20. Yoo, J.; Yoo, C.; Cho, Y.; Park, H.; Oh, H.B.; Seong, W.K. (2004). Antimicrobial resistance patterns (1999-2002) and characterization of ciprofloxacin resistant Neisseria gonorrhoeae in Korea. Sex. Transm. Dis. 31, 305-310. 